EMBRYARIDDLE
Aeronautical University

SCHOLARLY COMMONS

\section{International Journal of Aviation,} Aeronautics, and Aerospace

\title{
Examining the Impact of Overhearing In-Flight Cell-Phone Calls on Passenger Safety
}

Tianhua Li

Florida Institute of Technology, tli2017@my.fit.edu

Brooke E. Wheeler

Florida Institute of Technology, bwheeler@fit.edu

Debbie S. Carstens Ph.D., PMP

Florida Institute of Technology - Melbourne, carstens@fit.edu

Follow this and additional works at: https://commons.erau.edu/ijaaa

Part of the Human Factors Psychology Commons

\section{Scholarly Commons Citation}

Li, T., Wheeler, B. E., \& Carstens, D. S. (2020). Examining the Impact of Overhearing In-Flight Cell-Phone Calls on Passenger Safety. International Journal of Aviation, Aeronautics, and Aerospace, 7(2). https://doi.org/10.15394/ijaaa.2020.1443

This Article is brought to you for free and open access by the Journals at Scholarly Commons. It has been accepted for inclusion in International Journal of Aviation, Aeronautics, and Aerospace by an authorized administrator of Scholarly Commons. For more information, please contact commons@erau.edu. 
Approximately 58 people who are not wearing seatbelts are injured annually during turbulence in the United States (Hiatt, as cited in Davies, 2013). Davies (2013) also reported that two-thirds of the passengers, who were killed during turbulence accidents from 1980 to 2008 , overlooked illuminated seatbelt signs and did not fasten their seatbelts. This type of outcome from a lack of compliance could be disastrous from a passenger safety perspective. A pilot stated that sudden turbulence could throw passengers, who were not wearing seatbelts, out of their seats, and those passengers might hit armrests, carts, or even other passengers (as cited in Toohill, 2015). Thus, passengers who fail to comply with safety instructions may put themselves and other passengers at risk. For example, on July 6, 2013, Asiana Airlines Flight 214 hit the seawall when it was approaching the runway. According to the report from the National Transportation Safety Board (NTSB), two passengers were ejected from cabin windows and fatally injured because they did not fasten their seatbelts. If they had secured themselves before the impact, they might have survived the accident (Aarons, 2014). In the same year, on May 26, there were 12 occupants on board Singapore Airlines Flight SQ 308 that received injuries when it entered severe turbulence (Moran, 2013). Similarly, on December 28, 1997, United Airlines flight 826 encountered turbulence, which caused 74 injuries including one fatal injury. These examples illustrated that it is critical for flight passengers to follow safety instructions and fasten seatbelts.

Admittedly, some passengers choose not to fasten seatbelts even though they know they are required to do so. It is also possible that those passengers unintentionally ignore the instructions due to distractions and fail to seize the best opportunities to fasten seatbelts. Therefore, as Li and Dattel (2018) asserted, a passenger's attention to in-flight announcement instructions is significant and crucial to safety. Distraction of passengers could be caused by many factors, such as extraneous conversation. Examples include when passengers are engaged in conversations or are forced to listen to other passenger's conversations until the conversations cease.

The researchers identified two types of conversations between two individuals that can be overheard on commercial flights: one-sided conversation (e.g., cell-phone conversation) and two-sided conversation (e.g., face-to-face conversation). Currently, in the United States, all conversations between passengers in a cabin are in person. The use of cell phones is prohibited by the Federal Communications Commission (FCC) when the aircraft is airborne. However, under Title 47 of the Code of Federal Regulations (47 CFR) part 22, $\S 22.925$, if the aircraft is equipped with a mobile device that is able to eliminate the electronic interference, the cell-phone ban will not be in effect for the aircraft. Moreover, the U.S. Department of Transportation (DOT) announced that the FCC's regulations do not restrict the communications via $\mathrm{Wi}-\mathrm{Fi}$ that include existing voice communication applications, such as Skype, Apple Facetime, and Google Hangouts 
(Zhang, 2016). These applications are very similar to traditional cell phone calls. Even if the ban on cell phone conversations is not lifted, passengers can still have cell phone conversations during flights via the internet.

The European Union (EU) considered allowing passengers to converse over cell phones on aircraft with mobile devices equipped once the aircraft reached 10,000 feet ("European Union Approves," 2008). Currently, the EU has sent out new conditions to lift the ban on in-flight cell phone calls. Furthermore, Emirates airlines has allowed passengers to make cell phone calls on A380s; since 2008, nearly three million phone calls have been made ("Emirates," 2018; Kerr, 2012). Besides Emirates, many other airlines, including British Airways and Etihad, allowed in-flight phone calls (Cheslaw \& Brady, 2019). Therefore, cell phone calls are possible on some commercial flights.

Regarding the allowance of in-flight cell phone calls, a paramount concern is passengers' attention in the cabin. As mentioned above, if passengers pay little attention to instructions, they may fail to secure themselves in time, which could lead to injuries. Sheridan (2007) defined attention as "the focusing of sensory, motor, and/or mental resources on aspects of the environment to acquire knowledge" (p. 16). Both in-flight announcements and passengers' conversations are the aspects of the environment, to which passengers may attend. However, if these two external stimuli appear simultaneously, there could be a problem. Lien, Ruthruff, and Johnson (2006) asserted people are usually unable to multitask because they can hardly bypass the central bottleneck. Although sometimes people believe they are multitasking, in fact, individuals are only merely deciding what external stimuli should be attended to, based on their areas of focus (Endsley \& Jones, 2011; Sheridan, 2007). In this case, passengers will allocate their attention to the announcement and the conversation based on the perceived importance or interest. Admittedly, if passengers notice some keywords, such as emergency, in the announcement and realize the importance of the message, they could become more attentive to the announcement ( $\mathrm{Li} \&$ Dattel, 2018). However, if it is simply a general announcement that warns passengers of potential turbulence, it would be more likely that passengers will pay attention to conversations, especially when the conversations are intriguing.

There are two types of distracting situations with respect to conversations: engaging in the conversation and overhearing the conversation (Monk, Carroll, et al., 2004). Li and Dattel (2018) researched the influence of engaging in conversations on passengers' attention to flight announcements, as well as their compliance with instructions. They compared the passengers' performance when they are engaged in three types of conversations, including cell phone conversations (i.e., one-sided conversations), face-to-face conversations (i.e., two-sided conversations), and no conversation (i.e., the control group). The results indicated that conversations affected passengers' compliance with instructions. In 
comparison to not having conversations, cell-phone conversations (CPCs) and faceto-face conversations (FFCs) have negative effects on passengers' attention. The study also showed that the conversations impaired passengers' attention to announcements because the control group had significantly more retention of the announcement contents than the other two groups. However, there was no significant difference in any measurement between the CPC group and the FFC group. These two groups had equivalently performance. This research provided evidence to support that CPCs are not more distractive to passengers who are engaging in conversations when comparing with FFCs.

However, Li and Dattel (2018) focused on the performance of conversers; the influence on overhearers was not examined. The passengers who are involved in the conversations, either one-sided conversations or two-sided conversations, are able to acquire information from both sides (Li \& Dattel, 2018). By contrast, as for those who are overhearing conversations, a one-sided conversation is more difficult to understand and more annoying than a two-sided conversation because they do not know what the person on the other side of the phone is saying (Monk, Carroll, et al., 2004; Monk, Fellas, \& Ley, 2004). Therefore, it is more likely to cause an impairment of the abilities of the overhearers to perceive and understand announcements. Despite this, it can be assumed passengers who hear conversations should have more flexibility to focus on different external stimuli. Conversers must keep the focus on the conversations to show their respect, whereas overhearers can quickly shift their attention from conversations to announcements.

Emberson et al. (2010) stated that for overhearers, different conversations could lead to varying degrees of distraction. They tested the dialogue (i.e., twosided conversation), monologue (i.e., two-sided conversation with the same acoustic pattern), halfalogue (i.e., one-sided conversation), and no conversation. Participants overheard conversations while they were engaging in tasks, and there was only a significant difference between no conversation and the halfalogue. Afterward, Emberson et al. low-passed the sound files so that the acoustic pattern did not change, but the content was not understandable. It was found that the impairment of the attention was due to the unpredictability of the conversation. Researchers concluded that it was not the conversation that distracted participants from tasks, but rather the interruption of the content. In other words, for overhearers, a one-sided conversation should be more distracting than a two-sided conversation because they cannot acquire a half content of the dialogue. However, this is different for flight passengers. In the Emberson and colleagues' experiment, participants had to engage in the tasks, but passengers are more relaxed and flexible. Similarly, according to the need-to-listen effect, a one-sided conversation is more noticeable and distractive to other people (Galván, Vessal, \& Golley, 2013; Monk, Fellas, et al., 2004; Norman \& Bennett, 2014). If this theory is applicable to flight passengers, it can be implied that adjacent passengers could be distracted by cell- 
phone conversations from in-flight announcements to a more substantial degree than by face-to-face conversations.

Furthermore, the overhearer's annoyance with conversations is another problem. When some passengers want to rest on the aircraft, while other passengers are talking, they tend to be annoyed with the conversation. Therefore, it is also necessary to determine other passengers' annoyance before considering lifting the ban on cell phone calls onboard. Monk, Carroll, et al. (2004) and Monk, Fellas, et al. (2004) conducted research to understand why a cell-phone conversation is more annoying than a face-to-face conversation. They provided three plausible reasons, which were (a) different contents and volumes, (b) the need-to-listen effect, and (c) negative attitudes toward cell phones. The first reason means people tend to talk loudly on phones, or their ringtones are loud. Also, the content may contain selfpromotions. The second reason refers to the fact that other people can only hear one side of the conversation, so they want to know what the people on the other side of the phone are saying. The third reason is that cell phones were relatively new to people at that time, so they cannot ignore CPCs like they ignore FFCs. The results of these two studies showed that the need-to-listen effect is the reason that a CPC is annoying. In other words, the one-sided conversation is annoying, not CPCs specifically.

Based on the findings of Monk, Carroll, et al. (2004) and Monk, Fellas, et al. (2004), Norman and Bennett (2014) provided an alternative, reasonable explanation: unpredictable acoustics. This means overhearers are annoyed with one-sided conversations not because the contents are interrupted but because the acoustic patterns are interrupted. After the experiment, they found that when people do not understand the conversations (e.g., in other languages), a one-sided conversation is not annoying anymore. This result verified the explanation of the need-to-listen effect. If this is the case, other passengers would be annoyed with an adjacent passenger's cell-phone conversation because they cannot hear the other side of the phone. Another finding in this study was that if the content is intriguing, one-sided conversations are not more annoying than two-sided conversations (Norman \& Bennett, 2014).

In summary, the current ban on in-flight cell phone use is mainly due to electronic interference with avionics and ground cellular stations. With the advent of some modern technology, such as aircraft-based Wi-Fi, cell phone conversations onboard commercial airliners are possible. Therefore, the potential that passengers' attention to in-flight announcements could be impaired by CPCs should be under consideration. If CPCs have an adverse influence on passengers' attention, it will delay passengers' responses to announcement instructions, and passengers may receive injuries. Previous research demonstrated CPCs did not lead to more distraction for the passengers who were talking than FFCs. Specific to overhearers, CPCs can be more likely to attract people's attention, yet, can also be more 
annoying than FFCs. The problem with the findings of these studies is the research conducted involved random people from the public. Therefore, the results may not be applicable to passengers on commercial airliners, nor do they consider the impact of CPCs on observer passengers. The current study (a) examined the difference in the attention of the passengers, who overhear conversations, to inflight announcement instructions among different types of conversations, which could lead to passengers' injuries, (b) examined passengers' performance regarding compliance with safety instructions under the influence of conversations, and (c) identified the adjacent passengers' attitudes toward different conversations.

\section{Participants and Experimenters}

\section{Methods}

To determine an appropriate sample size, a power analysis was conducted. It showed that with a medium effect size, which was suggested by Cohen (1988), 28 participants were needed to acquire a power of 0.80 (Faul et al., 2013). There were 26 participants; two of the participants were excluded because the instructions were not clearly provided in the first two study sessions. All participants were students or faculty members at a university in Florida, who volunteered to participate in the simulation. The target population was defined as economic class passengers on commercial flights in the United States. Requirements for participation included fluency in English, normal hearing abilities, and flight passenger experience. Participants had chances to win a raffle prize, and some students were provided with extra credit. Among the participants, 16 individuals were male, and the other eight were female. Participants' age ranged from 18 to 54 years old $(M=25.08, S D=7.82)$. Participants reported that they took 4.83 flights on average annually with an $S D$ of 3.93, with a range of flights per year from 1 to 22.

Four experimenters were recruited. Experimenter A functioned as a flight attendant, who reminded participants to lower tray tables before raise-tray-table instructions. Experimenters B and C made conversations, which were pre-recorded. Experimenter D also acted as a flight attendant and recorded the safety announcements.

\section{Design}

The research was a within-subjects experimental design. The independent variable was the type of conversations: one-sided conversation (i.e., CPC), twosided conversation (i.e., FFC), and no conversation during announcements. Conversations were pre-recorded and volume-normalized to ensure the volume, tones, content, and other characteristics were the same in different sessions. The study design was modeled on the method used by Emberson et al. (2010). Moreover, the conversations' content was neutral (i.e., unremarkable) because if the content is intriguing, the degrees of annoyance with one-sided and two-sided conversations 
were equivalent (Norman \& Bennett, 2014). The dependent variables (DV) were (a) adjacent passengers' annoyance with conversations, (b) whether or not they listened to conversations, (c) whether or not they heard instructions clearly under the influence of conversations, (d) adjacent passengers' compliance with instructions, and (e) the response time for each action. The data of the first three DVs were acquired using a questionnaire. Compliance and response times were measured by observing their actions. During each simulation, a 4K camera recorded participants' behaviors so that the data could be collected efficiently and accurately.

The experiment was conducted in a lab room, which was set up to simulate a commercial aircraft cabin. The seat pitch was set at 32 inches to simulate real cabins. To determine an appropriate seat pitch, the information about short-haul and long-haul economic class seat pitches was retrieved from SeatGuru ("Shorthaul Economy," n.d.; "Long-haul Economy," n.d.). Only U.S. airlines were selected and analyzed. If the seat pitch was a range, the median was used. Descriptive statistical analysis found that for short-haul flights, the seat pitch ranged from 28 (Spirit) to 39 (JetBlue), and the median and the mean were both 32. As for longhaul, it varied between 30 (American, Hawaiian, and Skylanes) and 38 (Delta) with a mean of 33 and a median of 32. Therefore, the aircraft seats in the lab room were placed with an interval of 32 inches to simulate a realistic economic class cabin.

There were four sets of aircraft seats, a total of 12 seats. All the aircraft seats were equipped with seatbelts and tray tables, and only the back three rows were utilized in order to ensure that participants could use both seatbelts and tray tables. Two participants were in the middle seats of the second and last rows (Figure 1). Moreover, a mechanical speaker (speaker A) was placed underneath the middle seat of the third row to play announcements so that participants on the front seat and the back seat could hear the voice clearly at the same volume. A pair of stereo speakers (speaker B) were placed on the left and right seats of the third row respectively to play conversations. The placement of the speakers mirrored the sound of conversation with two conversers from different directions. There were 12 sessions of the simulation, each with two participants. The order of conversations and the order of scripts were switched in different sessions to counterbalance. Assigned conversations and order for each session are presented in Figure 2. 


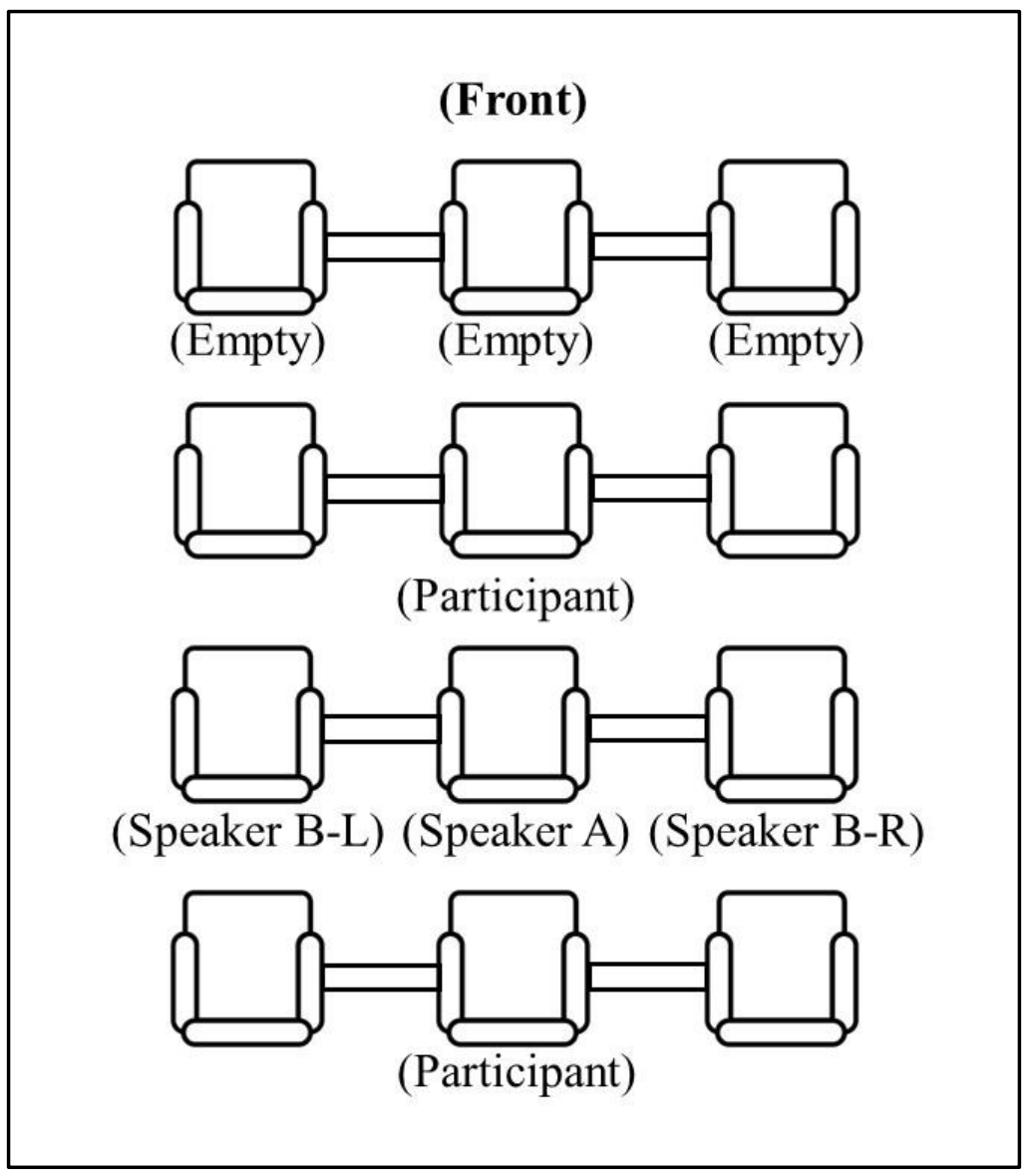

Figure 1. Lab setup and seat layout.

\begin{tabular}{|c|c|c|c|}
\hline Sessions & First Announcement & Second Announcement & Third Announcement \\
\hline 1,7 & One-sided Conversation (A) & Two-sided Conversation (B) & No Conversation \\
\hline 2,8 & Two-sided Conversation (B) & No Conversation & One-sided Conversation (A) \\
\hline 3,9 & No Conversation & One-sided Conversation (A) & Two-sided Conversation (B) \\
\hline 4,10 & One-sided Conversation (B) & Two-sided Conversation (A) & No Conversation \\
\hline 5,11 & Two-sided Conversation (A) & No Conversation & One-sided Conversation (B) \\
\hline 6,12 & No Conversation & One-sided Conversation (B) & Two-sided Conversation (A) \\
\hline
\end{tabular}

Figure 2. Conversation order for each session. 


\section{Procedures}

Before the simulations started, the instructions were read to each participant. Participants were told to assume they were aboard a commercial aircraft and needed to obey all current flight regulations. A few magazines were put in the seat pockets so that participants would not feel bored. However, during the simulation, they were prohibited from talking, using cell phones, listening to music, or leaving their seats. Also, they were informed of the allowance of in-flight cell phone calls, and participants were asked to listen to and adhere to in-flight announcements. The responses needed to be observable. After that, participants were seated, and they were told not to fasten seatbelts at that time. When the simulation began, conversations were played, based on the assigned conversation order (Figure 2) at 3:40, 7:40, and 11:40 minutes, respectively. Three announcements were played at the fourth, eighth, and 12th minutes. The four-minute intervals were selected to allow participants to calm down and no longer anticipate the next announcement. The first announcement asked passengers to fasten seatbelts. The second announcement instructed them to raise tray tables. Between the first and second announcements, a flight attendant walked around and asked participants to lower tray tables. The last announcement told passengers to physically check that their seatbelts had been fastened. One minute after the last announcement, the simulation ended. During each session, a 4K camera recorded participants' behaviors to check for compliance with announcements and response times. After the simulation was over, participants were given questionnaires to ask about their attention and attitudes toward conversations.

\section{Results and Discussion}

The current study examined the effect of types of conversations on (a) annoyance with conversations, (b) whether or not they listened to conversations, (c) whether or not they heard instructions clearly under the influence of conversations, (d) whether or not they made responses to instructions, and (e) the response time for each action. For all statistical tests, the alpha-value was set at 0.05 . The values below 0.05 were considered significant results, and the values that were between 0.05 and 0.10 were considered marginal results.

\section{Annoyance}

As the experiment was a within-subjects design, a paired-samples $t$-test was run to analyze the effect of the conversation type on the annoyance with conversations. The result showed a marginally significant difference: $t(23)=3.09$, $p<.10$. Participants reported a higher level of annoyance with CPCs $(M=3.54$, $S D=.78)$ compared to FFCs $(M=2.83, S D=.76)$.

The results supported the findings of Monk, Carroll, et al. (2004), Monk, Fellas, et al. (2004), and Norman and Bennett's (2014) findings that if other people could understand conversations, one-sided conversations were more annoying than 
two-sided conversations. Monk, Fellas, et al. gave an explanation, which was the need-to-listen effect. It means overhearers want to know what the other speaker is saying, but they are unable to acquire that information. As a result, they are annoyed by hearing only one-sided conversations. A solution is to make the cell-phone conversation a two-sided conversation by asking passengers to turn on the speaker. This is recommended for future studies.

\section{Listening to Conversations}

A paired-samples $t$-test showed no significant difference in the extent to which participants listened to conversations, $t(23)=.27, p=.79$. It revealed that CPCs $(M=3.88, S D=.90)$ had no significant difference from FFCs $(M=3.83$, $S D=.82)$. The result contradicted previous research. Monk, Fellas, et al. (2004), Emberson et al. (2010), Galván et al. (2013), and Norman and Bennett (2014) announced that one-sided conversations were more noticeable than two-sided conversations. An explanation could be the effect of contaminants. Therefore, another statistical analysis was run with outliers absent. Jackknife distances analysis was utilized to identify potential outliers, and the critical distance was found to be 2.75. Four cases were excluded as outliers due to exceeding the critical distance. The result was still not significant: $t(19)=.44, p=.67(d=.10)$. The result demonstrated that passengers paid an equivalent amount of attention to CPCs and FFCs while an announcement was being played. Another possible explanation could be the difference in experimental conditions. To be specific, in three past studies, experiments were conducted in a bus station, on trains, and in waiting rooms; whereas, in the current study, participants were sitting in a simulated aircraft cabin with engine sound as background noise, which could mitigate additional annoyance caused by conversations. Although the difference in attention is appeared to be minimal, it is necessary to report a power of .07 (Faul et al., 2013), and a study with a larger sample size is recommended.

\section{Hear Instructions Clearly}

Before the main analysis was conducted, an outlier was detected. Jackknife distances analysis showed the critical value was 3.27, and one case was not within the range. This participant scored 5, 5, and 5 for three items, including a reversescored item, so the case was excluded from this analysis. As there were three, within-subjects levels that were tested, a one-way, within-subjects ANOVA was run, and the sphericity assumption was satisfactory. The result showed a marginal difference: $F(1,22)=4.12, p=.06$ (partial $\left.\eta^{2}=.16\right)$, and power $=.49$ (Figure 3 ). As the difference was marginally significant, pairwise comparisons were still run. A Bonferroni procedure was applied, but no significant effect was detected. The $p$ values for the comparisons between (a) CPC and FFC, (b) FFC and no conversation, and (c) no conversation and CPC were .59, 1.00, and .16, respectively. Therefore, participants heard instructions clearly to the same extent. A plausible explanation was that participants knew announcements, which began with "ladies and 
gentlemen", were more important than conversations, so they were not significantly affected by other people's conversations.

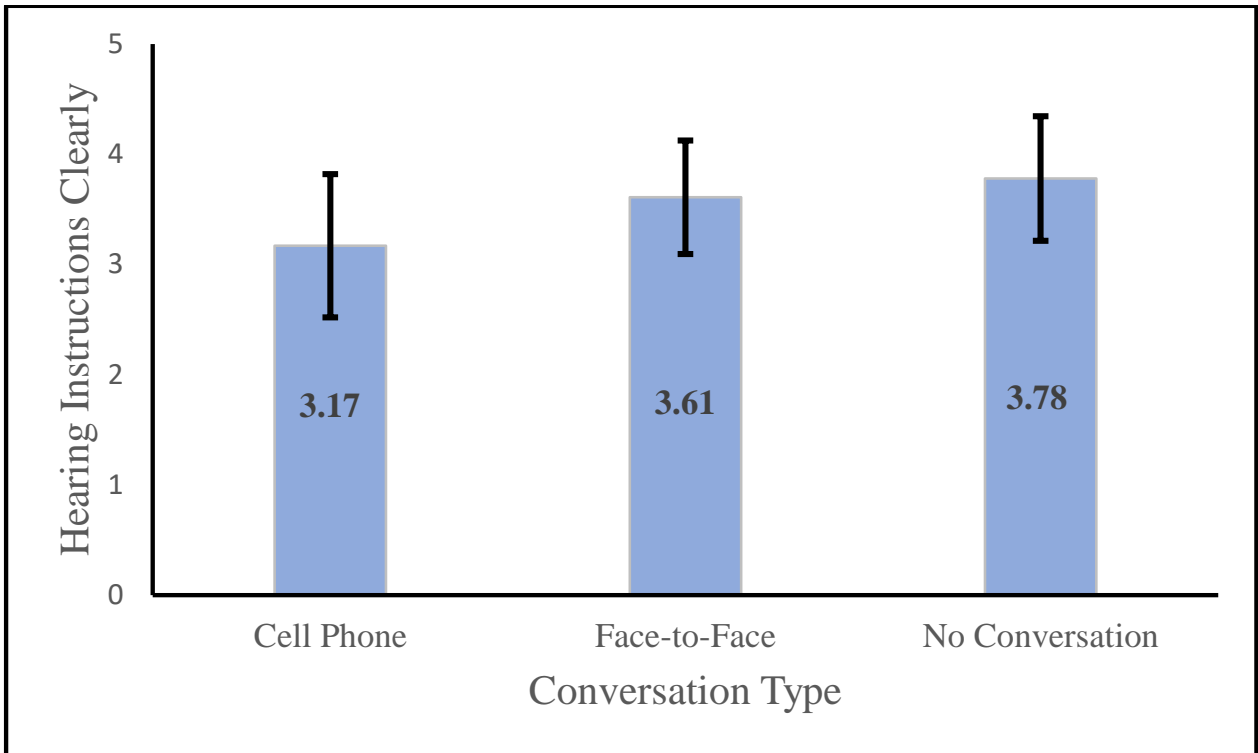

Figure 3. Hearing instructions clearly by type of conversation.

\section{Compliance with Instructions}

Two variables were categorical, and the independent variable included three levels. The effects were within-subjects. Therefore, a Cochran's Q test was used to discover the effect. The results showed no significant difference among levels, $\chi^{2}(2)=2.46, p=.29$. The frequencies for each level are shown in Figure 4. The outcome demonstrated that overhearing conversations did not negatively impact passengers' safety behaviors, which included fastening seatbelts, closing tray tables, and checking seatbelts. However, the effect of conversations on overhearers is different from the effect on conversers. Li and Dattel (2018) studied conversers' behaviors and asserted that, although there was no significant difference between CPCs and FFCs regarding compliance, the control group performed better in some conditions than the CPC group or FFC group. A plausible explanation about the deviation in the results of two studies is that conversers wanted to show their respects to other speakers and had to attend to dialogues. In this case, they did not have full control over the engagement in conversations because they are already in them. On the other hand, overhearers were able to choose whether or not they listen to conversations without social concerns. In other words, overhearers had the ability to switch their attention between announcements and conversations freely, depending on their perceived priorities and interests. This implies that conversations had less adverse impacts on other passengers than conversers, those who were directly involved in conversations. 


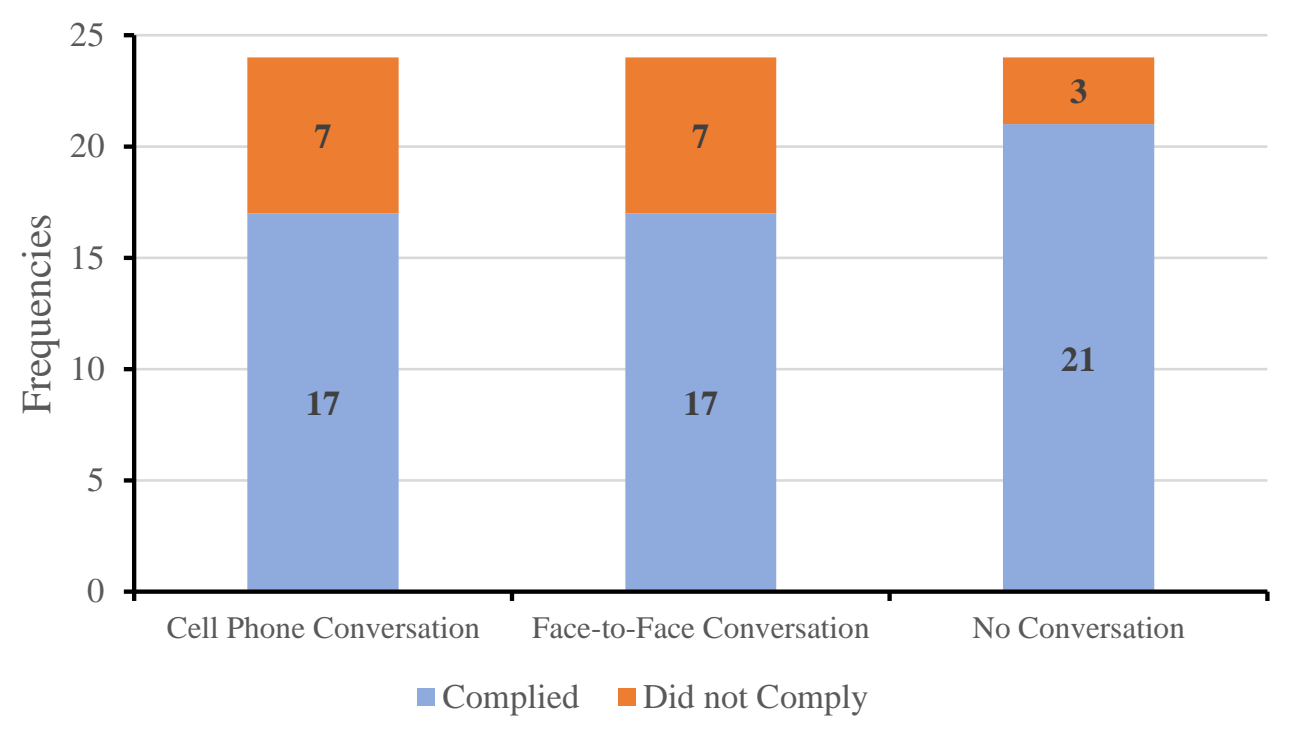

Figure 4. Compliance with safety instructions by type of conversation.

\section{Response Time}

A within-subjects ANOVA was conducted, and the homogeneity of covariance was satisfactory. There was no significant difference in the response time among conversations, $F(1,23)=.09, p=.76$. The power was low, only .06 . A possible reason was that there were only 11 valid cases. Some participants did not comply with instructions, and therefore, their response times were missing. For the response time under the influence of $\mathrm{CPCs}$, FFCs, and no conversation, the percentages of missing data were $29.17 \%, 29.17 \%$, and $12.50 \%$, respectively. To proceed with the analysis, an effective way is to replace the missing data with the means, 1610.59, 2042.35, and $1450.95 \mathrm{~ms}$ for CPCs, FFCs, and no conversation, respectively. It appeared that the data in all conditions were also missing randomly. Therefore, all the missing response times were substituted with corresponding means.

After substituting with new data, Jackknife distances analysis was conducted to identify outliers. Two outliers were found and excluded with a critical distance of 3.27. The Mauchly's Test of Sphericity showed that the sphericity assumption was violated, $\chi^{2}(2)=9.67, p=.01$, and thus the Greenhouse-Geisser correction was used. The result was significant, $F(1.45,30.36)=8.25, p<.01$. A Bonferroni post-hoc test indicated that participants' response time under FFCs was significantly longer than during CPCs or no conversation. It indicated that participants have better performance initiating responses to instructions when hearing CPCs or no conversation than FFCs. There was no other difference. The means and S.D.s are shown in Figure 5. One plausible explanation was that FFCs 
included more content because both sides could be heard, which might take more resources and a longer time for people to process the information.

Li and Dattel (2018) reported no significant difference in conversers' response times among the CPC group, FFC group, and the control group. Descriptive statistics showed that the mean response times in this study were around two seconds, and S.D.s were small. However, Li and Dattel (2018) found much longer mean reaction times, which could be over eight seconds, and SDs that were relatively large as well. The high variability in that study weakened the difference among groups. The reason could be overhearers had more informationprocessing resources than conversers. Thus, conversers' response times were longer and had more variation.

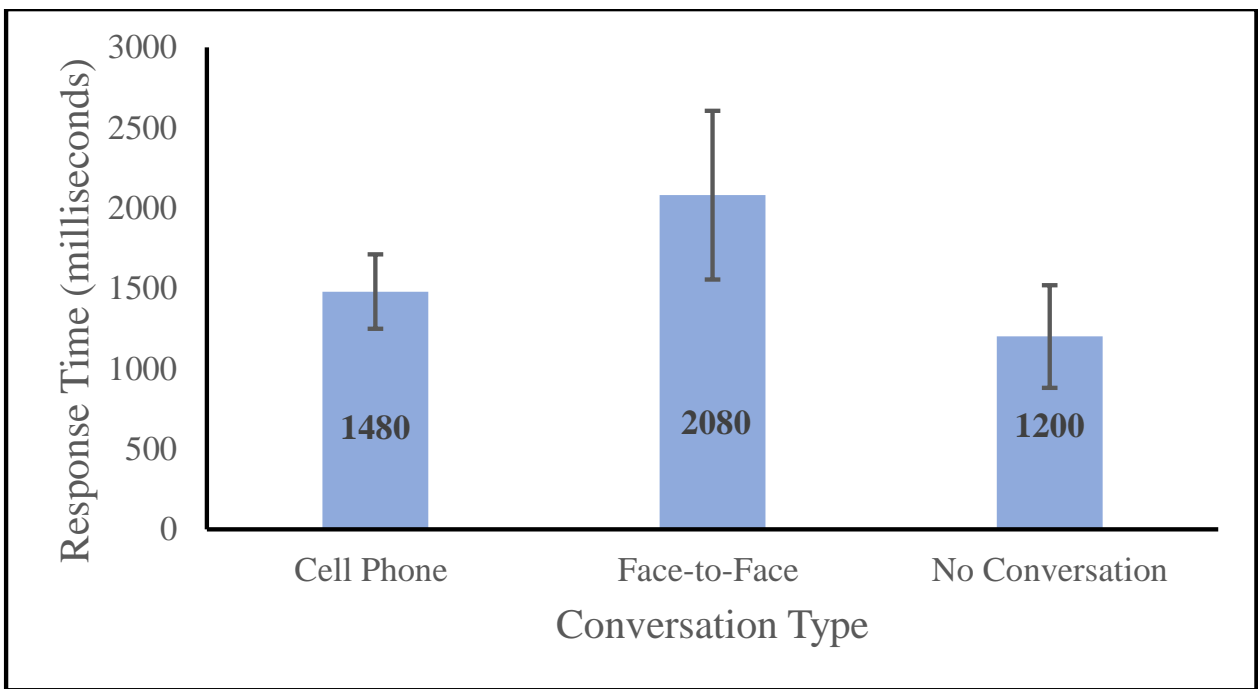

Figure 5. Response time for following instructions by conversation type.

\section{Limitation and Delimitation}

A limitation of the study was the flight experience of participants. A participant with little flight experience might spend longer initiating responses to instructions; however, a frequent flier might be very familiar with the actions of fastening seatbelts and raising tray tables as well as the standard announcements. A major delimitation was the simulation setting. Due to safety concerns and ethics, the experiment was conducted in a laboratory room where participants did not feel the aircraft was shaking, so they would not be very concerned about their safety. Although the sampling method slightly restricted generalizability, all participants were screened prior to participation for experience traveling by commercial airliner. Additionally, the wide age range of participants indicates that results should be generalizable to the broader population of air travelers. Also, the cabin was 
designed to be as realistic as possible through the use of actual aircraft seats and accurate seat pitch lending the study a reasonably high ecological validity.

\section{Conclusion}

The purpose of the current study was to (a) examine overhearers' annoyance with conversations during flights, (b) discover their attention to announcements under the influence of those conversations, and (c) identify their performance on following instructions.

The results demonstrated that passengers were more annoyed with CPCs in comparison to FFCs. This may be due to the need-to-listen effect (Monk, Fellas, et al., 2004). Findings were aligned with previous research (Monk, Carroll, et al., 2004; Monk, Fellas, et al., 2004; Norman \& Bennett, 2014). On the contrary, passengers did not listen to CPCs to a larger degree than FFCs or find instructions less clear, while overhearing CPCs compared to FFCs. In other words, CPCs were not more distracting than FFCs. Also, there was no difference from the no-conversation condition either. It demonstrated CPC, FFC, and no-conversation conditions had equivalent effects on other passengers' attention. The findings were different from previous studies, which presented that CPCs were more noticeable than FFCs because of the interruption of contents (Emberson et al., 2010; Galván et al., 2013; Monk, Fellas, et al., 2004; Norman \& Bennett, 2014). With respect to performance, passengers have similar compliance in different situations. No matter which type of conversations they overheard, they all complied with instructions to similar degrees. However, when hearing FFCs, participants tended to have longer response times to initiate actions, compared to CPCs and no conversation.

Therefore, cell-phone calls can be considered for being allowed and supported in the United States. A cell-phone call does not bring additional, potential harm to passengers' safety, and it is somewhat less likely to distract passengers from safety announcements than face-to-face dialogues. Nevertheless, regulators should take other passengers' attitudes toward CPCs into consideration. They may think about restricting talking zones, loudness, and times. Alternatively, passengers can be required to turn on speakers when talking on cell phones to make the CPC a two-sided conversation, which might mitigate other passengers' annoyance. 


\section{References}

Aarons, R. N. (2014). Lessons learned-Asiana flight 214. Business \& Commercial Aviation, 110(8), 68-71. Retrieved from http://search.proquest.com. ezproxy.libproxy.db.erau.edu/docview/1647367817?accountid=27203

Cheslaw, L., \& Brady, P. (2019). Can you text on airplane? A guide to in-flight phone use. Condé Nast Traveler. Retrieved from https://www.cntraveler.com/stories/2014-06-16/everything-you-need-toknow-about-using-a-cell-phone-on-a-plane

Cohen, J. (1988). Statistical power analysis for the behavioral sciences. Mahwah, NJ: Lawrence Erlbaum.

Davies, A. (2013, July 11). Yes, you should buckle your seatbelt on an airplane. Business Insider. Retrieved from http://www.businessinsider.com/whyyou-keep-your-seatbelt-on-in-a-plane-2013-7

Emberson, L. L., Lupyan, G., Goldstein, M. H., \& Spivey, M. J. (2010). Overheard cell-phone conversations: When less speech is more distracting. Psychological Science, 21(10), 1383-1388. doi:10.1177/0956797610382126

Emirates celebrates 10 years of mobile phone connectivity on flights. (2018, March 26). Emirates. Retrieved from https://www.emirates.com/mediacentre/emirates-celebrates-10-years-of-mobile-phone-connectivity-onflights/

Endsley, M. R., \& Jones, D. G. (2011). Designing for situation awareness: An approach to user-centered design. Boca Raton, FL: CRC.

European Union approves cell phone for flights; The E.U. plan would allow airline passengers to use cell phone voice service once flights have reached an altitude of 10,000 feet. (2008, April 7). InformationWeek. Retrieved from https://go-gale-com.portal.lib.fit.edu/ps/i.do? p=ITOF\&u= melb26933\&id=GALE\% 7CA177577447\&v=2.1\&it=r\&sid=summon

Faul, F., Erdfelder, E., Buchner, A., \& Lang, A.-G. (2013). G*Power Version 3.1.7 [Computer software]. Uiversität Kiel, Germany. Retrieved from http://www.psycho.uni-duesseldorf.de/abteilungen/aap/gpower3/ download-and-register

Galván, V. V., Vessal, R. S., \& Golley, M. T. (2013). The effects of cell phone conversations on the attention and memory of bystanders. PLoS One, 8, e58579. doi:10.1371/journal.pone.0058579

Kerr, F. (2012, October, 8). Emirates airlines allows in-flight cell phone catting. Cnet. Retrieved from https://www.cnet.com/news/emirates-airlinesallows-in-flight-cell-phone-chatting/

Li, T., \& Dattel, A. R. (2018). Comparing the distraction of cell phone conversations to in-person conversations on a simulated commercial 
flight. International Journal of Aviation, Aeronautics, and Aerospace, 5(2). doi:10.15394/ijaaa.2018.1218

Lien, M., Ruthruff, E., \& Johnston, J. C. (2006). Attentional limitations in doing two tasks at once. Current Directions in Psychological Science, 15, 89-93. doi:10.1111/j.0963-7214.2006.00413.x

Long-haul economy class comparison chart. (n.d.). In SeatGuru by TripAdvisor. Retrieved from https://www.seatguru.com/charts/longhaul_economy.php

Monk. A., Carroll, J., Parker, S., \& Blythe, M. (2004). Why are mobile phones annoying? Behaviour \& Information Techonology, 23(1), 33-41. doi:10.1080/01449290310001638496

Monk, A., Fellas, E., \& Ley, E. (2004). Hearing only one side of normal and mobile phone conversations. Behavious \& Information Techonology, 23(5), 301-305. doi:10.1080/01449290410001712744

Moran, L. (2013, June 4). Passengers can't keep breakfast down when plane hits turbulence mid-meal. Daily News. Retrieved from http://www.nydailynews.com/news/world/breakfast-flying-plan-hitsturbulence-article-1.1362435

Norman, B., \& Bennett, D. (2014). Are mobile phone conversations always so annoying? The 'need-to-listen' effect re-visited. Behavious \& Information Technology, 33(12), 1294-1305. doi:10.1080/0144929X.2013.876098

Sheridan, T. B. (2007). Attention and its allocation: Fragments of a model. In A. F. Kramer, D. A. Wiegmann, \& A. Kirlik (Eds.), Human technology interaction series: Attention: From theory to practice (pp. 16-26). Oxford, England: Oxford University Press.

Short-haul economy class comparison chart. (n.d.). In SeatGuru by TripAdvisor. Retrieved January 2019 from https://www.seatguru.com/charts/ shorthaul_economy.php

Toohill, K. (2015, May 10). The real reason you should wear your seat belt on airplanes. Attn: Retrieved from http://www.attn.com/stories/1635/why-itsimportant-wear-your-seatbelt-airplane

Zhang, B. (2016, December 12). The U.S. government may allow in-flight phone calls, and people are freaking out. Business Insider. Retrieved from http://www.businessinsider.com/cell-phone-calls-airlines-dot-fcc-2016-12 